\title{
NOTAS SÔBRE CULICIDAE (DIPTERA)
}

\section{2 - A larva, a pupa e alguns dados biológicos de Aedes (Finlaya) fluviatilis Lutz, 1904 *}

\author{
O. P. Forattini $* *$ \\ E. X. RABello ***
}

Em Howard, Dyar e Knab (1917)" encontramos a primeira descrição detalhada da forma larvária de Aedes (Finlaya) fluviatilis Lutz, 1904. Maiores dados foram posteriormente acrescentados por Bonne e Bonne-Wepster (1925)" e Senevet e Abonnenc (1939) ". Lane $(1953)^{4}$ fornece algumas particularidades sôbre a pupa.

\section{AEDES (FINLAYA) FLUVIATILIS LUTZ, 1904.}

Larva (Figs. ns. 1 e 2). - Cápsula cefálica bem quitinizada. Antena escura, com espiculosidade esparsa; a cerda terminal dêsse órgão (n. 10) é grossa, alongada e de extremidade romba; a cerda antenal (n. 11) é dotada de dois a cinco ramos e implantada, aproximadamente, na região média. A cerda postclipeal (n. 4) é pequena e bi ou trirramificada na porção distal; as frontais são longas e ramificadas a partir da base, a interna (n. 5), com quatro ou seis ramos, a média (n. 6) com dois, e a externa (n. 7) com seis a oito. A cerda occipital interna (n. 8) é longa e simples, enquanto que a externa (n. 9) é birramificada. A cerda supraorbital (n. 14) é delgada e bífida. O mento apresenta contôrno triangular, possui um dente mediano e cêrca de dez ou onze outros laterais, dos quais os anteriores são rombos e os posteriores de extremidade aguçada.

No protórax, a cerda acessória dorsal (n. 0) é pequena e ramificada; as cerdas protorácicas submedianas (ns. 1-3) acham-se inseridas em placa quitinosa comum, sendo as ns. 1 e 3 longas e penadas, enquanto que a n. 2 é mais curta, fina e simples; das cerdas dorsolaterais

Recebido para publicação cm 11-4-61.

* Trabalho do Departamento de Parasitologia da Faculdade de Higiene e Saúde Pública da Universidade de São Paulo (Prof. Dr. José de Oliveira Coutinho) e do Departamento de Zoologia da Secretaria da Agricultura do Estado de São Paulo (Dr. Lindolpho R. Guimarães). Realizado com auxílio do Conselho Nacional de Pesquisas.

** Professor Adjunto.

**** Biologista. 
(ns. 4-7), a n. 4 é fina e simples e as ns. 5-7 são longas e penadas, o mesmo observando-se quanto à ventrolateral (n. 8) ; a fórmula das cerdas protorácicas apresenta-se com os seguintes aspectos:

$$
\begin{aligned}
& 2.1 .1-1-1-1-4-2 \\
& 3.1 .1-1-1-1-5-2 \\
& 3.1 .1-1-1-1-3-2
\end{aligned}
$$

As cerdas propleurais (ns. 9-12) são pouco desenvolvidas, inseridas em placa de contôrno circular, três delas são longas e simples e uma mais curta e bifurcada. No mesotórax, as cerdas dorsolaterais apresentam-se com o seguinte aspecto: a n. 1 é longa, penada e única ou bifurcada, a n. 2 pequena e bifurcada, a n. 3 fina e simples, a n. 4 fina e bifurcada, a n. 5 longa, grossa e penada, as ns. 6 e 7 inseridas em base comum e longas e penadas, a primeira delas é única enquanto que a outra é múltipla, dotada de cêrca de dez ramos; a cerda ventrolateral (n. 8) é longa, penada e múltipla. As cerdas mesopleurais (ns. 9-12) formam conjunto no qual duas delas são únicas, uma muito longa e outra múltipla dotada de numerosos ramos. No metatórax as cerdas dorsolaterais tem o aspecto seguinte, a n. 1 pequena e com três ou mais ramificações, a n. 2 fina e simples, a n. 3 curta e com seis ou mais ramos, a n. 4 fina e bifurcada, as ns. 5 e 6 finas e simples, a n. 7 desenvolvida, múltipla e penada; a cerda ventrolateral (n. 8) é pequena e com várias ramificações. As cerdas metapleurais (ns. 9-12) são longas e penadas, exceto uma, que é fina, curta e simples.

No II segmento abdominal, as cerdas dorsais são pequenas e com o seguinte aspecto: a n. 1 curta e bífida ou com escassas ramificações, a n. 2 curta e simples, a n. 3 curta e plurirramificada, a n. 4 longa e simples, a n. 5 curta e com quatro a cinco ramos; a cerda lateral superior (n. 6) apresenta-se dupla, grossa, longa e penada, enquanto que a lateral inferior (n. 7) é menor, fina e simples ou bifurcada.

No VIII segmento abdominal, as cerdas ns. 1,2 e 4 são finas e simples, a n. 3 é desenvolvida, penada e múltipla com cêrca de nove ramos, a n. 5 também é múltipla, com três ou mais ramificações. O pecten dêste segmento é constituído por numerosos elementos curtos, dispostos em três ou mais fileiras e dotados de extremidade distal franjada. O sifão respiratório apresenta-se bem quitinizado e escuro, com índice sifonal variando ao redor de 2,7 nos nossos exemplares. 0 tufo sifonal (n. 1) é único, penado e com número de ramos variável ao redor de dez. O pecten sifonal é formado por fileira de elementos bem quitinizados e afilados, tendo, os mais distalmente situados, cinco a seis dentículos basais de tamanhos variáveis. A cerda apicodorsal (n. 2) é curta e simples. No lobo espiracular, das cerdas da válvula dorsal, a proximal (n. 6) é simples e a distal (n. 7) é bi ou trirramificada. 
O lobo anal apresenta a sela bem quitinizada e as brânquias bastante longas, com cêrca de três vêzes o comprimento do lobo. A cerda lateral (n. 1) é fina, simples e inserida na margem do ângulo posterolateral da referida sela. A cerda interna da escôva dorsal (n. 2) é múltipla e formada por cêrca de dez elementos lisos, ao passo que a externa (n. 3) é simples, lisa e longa. A escôva ventral (n. 4) é constituída por conjunto de sete a nove cerdas múltiplas.

Pupa (Fig. n. 3). - Aspecto geral escuro, bem quitinizada, de maneira mais intensa na trompa respiratória. Esta, é de contôrno cônico, ligeiramente triangular, revestida de fino reticulado e dotada de margens lisas. O comprimento é pouco maior do que duas vêzes o valor da largura máxima.

No cefalotórax observa-se que as cerdas postoculares são longas e finas, sendo a superior (n. 1) bífida, enquanto que as outras (ns. 2 e 3) são comumente simples. As anterotorácicas anteriores (ns. 4 e 5) são longas e bífidas, sendo a superior (n. 5) mais comprida. Das setas anterotorácicas posteriores, a inferior (n. 6) é curta e fina, e a superior (n. 7) é desenvolvida e trífida. A cerda dorsal (n. 8) apresenta-se fina e, via de regra, trifurcada, ao passo que a supra-alar (n. 9) é simples e longa. As setas posterotorácicas (ns. 10, 11 e 12) são simples, sendo a média ( $n$. 11) a mais longa.

O abdome apresenta os segmentos pigmentados na porção mediana da face dorsal. A paleta natatória possui espiculosidade muito fina, pouco mais evidente nas regiões marginais dêsse órgão. $O$ índice da pá varia ao redor de 1,1. No I segmento observa-se a cerda $H$ pequena e simples, a $K$ longa, simples ou bífida ou ligeiramente penada, a $L$ curta e trirramificada, a $M$ com quatro ou cinco ramificações, a $S$ de comprimento médio e com cêrca de cinco ramos, a $T$ longa e bífida ou trífida, a $U$ pequena e simples. A cerda $A$ apresenta-se muito reduzida e simples, nos segmentos II-VI, ao passo que se acha desenvolvida e múltipla nos demais, dotada de cinco ou seis ramos lisos no VII e cêrca de dez, penados, no VIII. A cerda $A$ ' é longa e simples, no segmento VIII. A seta $B$ é longa, simples ou bífida em II-VI, e curta, fina e simples no VII. A cerda $C$ é de tamanho médio, simples ou com três ramos nos segmentos II, III, VI e VII, e alongada e bífida nos IV e V. A seta $C^{\prime}$ é pequena e simples. A cerda $D$ apresenta-se simples e alongada nos segmentos III-VII. O mesmo se observa quanto à cerda $E$ nos VI e VII. A seta n. 1 é longa e bífida no anel II, longa e simples nos III-VI, média e trífida no VII. A n. 2 é longa e trífida nos II e VI, média, simples ou bífida nos III-V, longa e simples no VII. A n. 3 apresenta-se longa e bífida no segmento II. A n. 4 é média é bífida em II, tornando-se mais longa e simples ou bífida nos III-VII. A n. 5 é sempre rudimentar. A n. 6 é curta e com 
dois ou três ramos. A n. 7 apresenta-se nos segmentos IV e $\mathrm{V}$, Ionga e simples. A n. 8 é muito curta e simples em III-V e VII, sendo mais alongada no VI. A cerda $x$, da paleta, é longa e simples.

Material examinado. - 25 larvas e pupas que deram origem, em condições de laboratório, a outros tantos exemplares adultos (15 machos e 10 fêmeas). Êste material foi coletado em criadouros instalados em agua retida em buracos de rochas, nas margens do Rio Claro, Município de Salesópolis, Estado de São Paulo, Brasil, em XI/1960.

Dados biológicos. - Os criadouros típicos desta espécie são constituídos por coleções de água doce, limpa e coletada em escavações de rochas localizadas nas margens de cursos acidentados. As oviposições são geralmente realizadas nesses buracos e, por ocasiáo das chuvas, dá-se a inundação dos mesmos e a subsequiente eclosão dos ovos. Contudo, êste mosquito pode ser encontrado criando-se em ambientes diferentes, naturais ou artificiais. Dessa maneira, foi encontrado desenvolvendo-se também nos seguintes criadouros: $\left.1941^{1}\right)$

Buracos em árvores (Bonne e Bonne-Wepster, 1925\%, Anduze,

Barricas para a coleta de água de chuva (Bonne e Bonne-Wepster, $\left.1925^{\circ}\right)$.

Recipientes circulares, anelados, de cimento, utilizados em parques e jardins para evitar o acesso de formigas às plantas (Soper e Serafim Jr., $1933^{\top}$ ).

Latas vazias e recipientes metálicos diversos (Senevet e Abonnenc, $\left.1939^{6}\right)$.

Vasos para flôres, em cemitérios (Lane, $1961{ }^{\circ}$ ).

As formas imaturas têm sido encontradas freqüentemente associadas a outras de várias espécies, como do gênero Culex e as do Aedes aegypti (Anduze, 1941 ${ }^{1}$ ).

Por êsses dados pode-se verificar que êste mosquito é espécie que possui acentuada tendência a se aproximar da habitação humana, dessa maneira adquirindo hábitos de domesticidade.

\section{RES U M O}

Os autores redescrevem as formas imaturas, larva e pupa, do Aedes (Finlaya) fluviatilis Lutz, 1904, a partir de material coletado no Município de Salesópolis, Estado de São Paulo, Brasil. São ainda fornecidos alguns dados sôbre os locais preferidos para a criação desta espécie. 


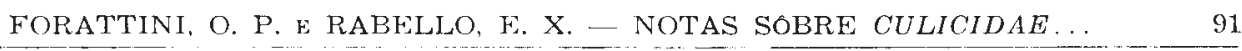

S U M M A R Y

The larva and pupa of Aedes (Finlaya) fluviatilis Lutz, 1904 are redescribed. These immature stages was collected at the Municipio of Salesópolis in the State of São Paulo, Brazil. Some data about breeding places are given.

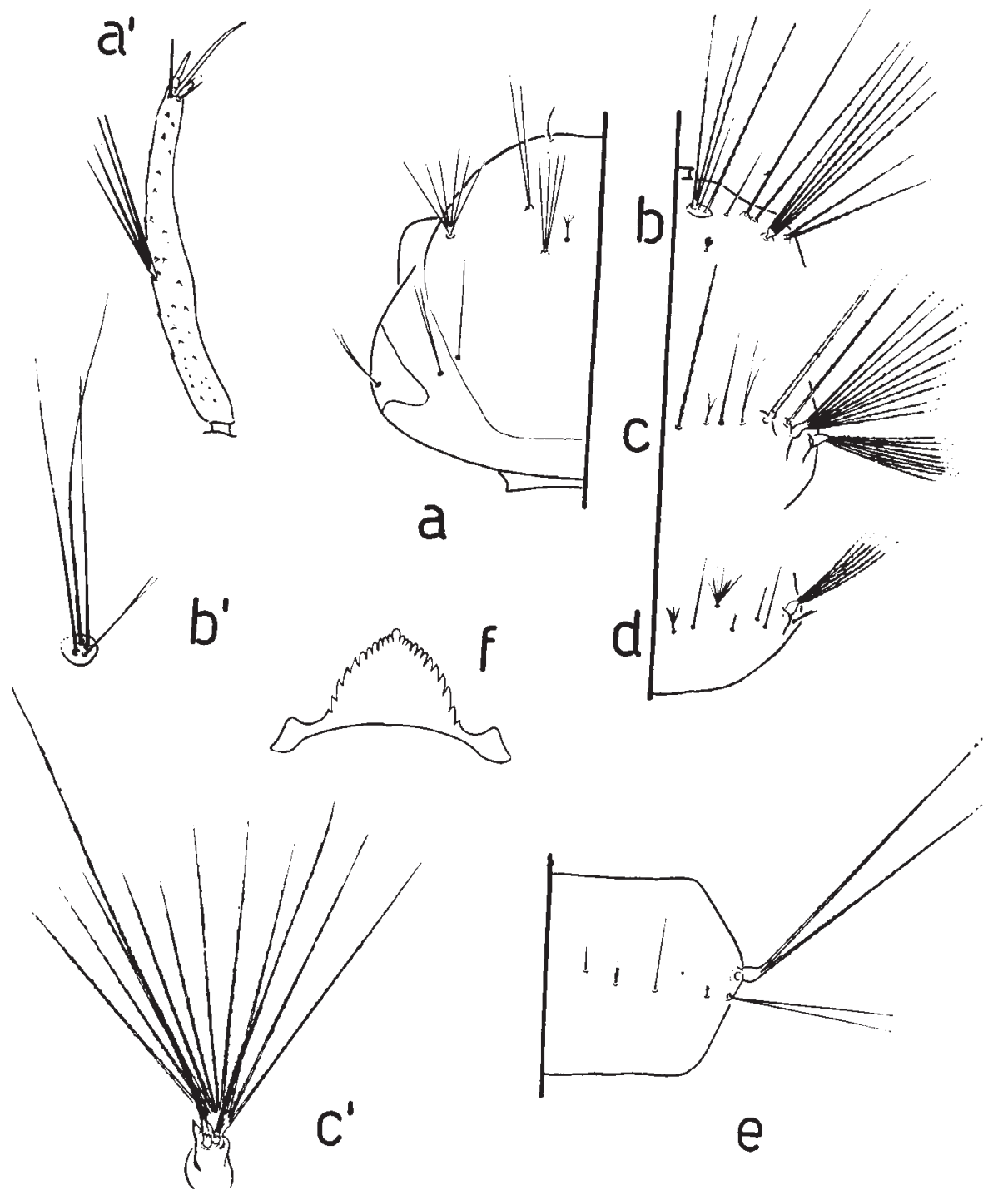

Fig. 1 - Aedes fluviatilis. Larva.

a -.. cápsula cefálica; a' - antena;

b - protorax; b' - cerdas propleurais (ns, 9-12):

"- mesotorax: "- cerdas mesopleurais (ns. 9-12);

d- metatórax;

c -.- II segmento abdominal;

f - mento. 


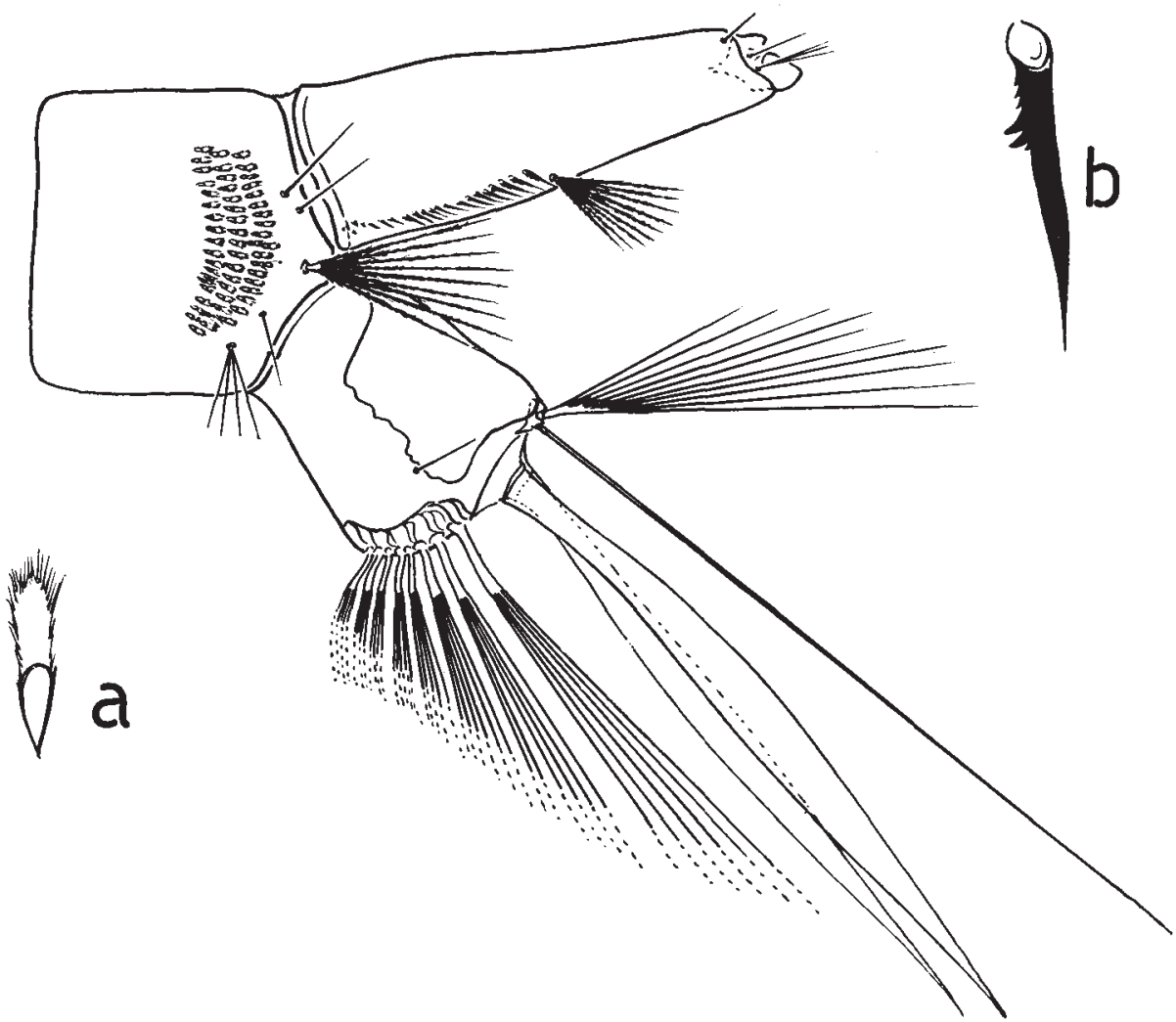

Fig. 2 - Aedes fluviatilis. Larva, últimos segmentos abdominais.

a - elemento do pecten do VIII segmento;

b -- elemento do pecten sifonal. 

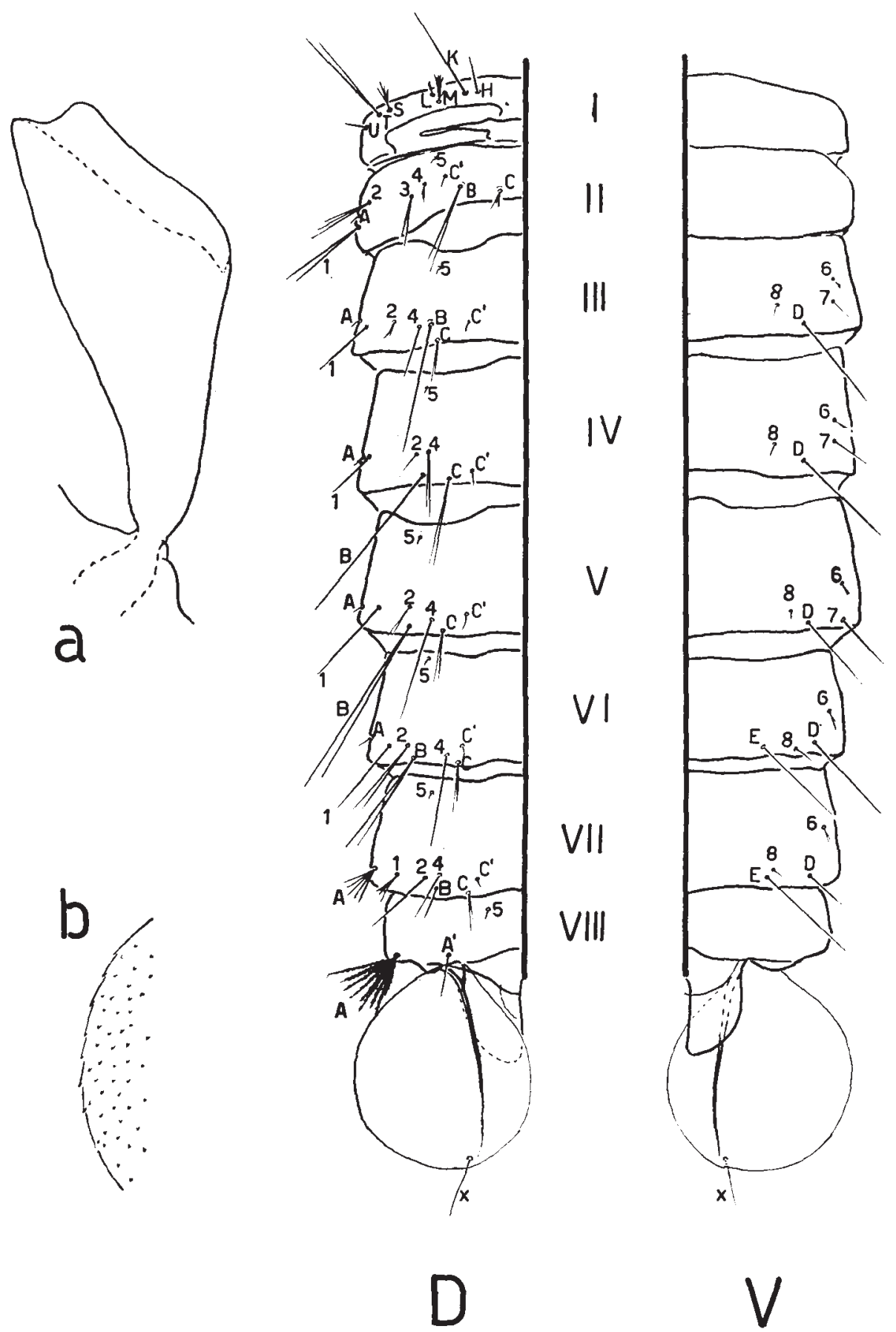

Fig. 3 - Aedes fluviatilis. Pupa

a - contôrno da trompa respiratória:

b - porcão marginal da paleta natatória;

D - face dorsal dos segmentos abdominais;

$\mathrm{V}$-- face ventral dos segmentos abdominais. 


\section{REFERENCIAS}

1. Anduze, P. J. Anotaciones sobre los zancudos del Estado Carabobo, Venezuela (Diptera, Culicidae). Rev. Sanid. Asist. soc., 6:491-508, 1941.

2. Bonne, C. \& Bonne-Wepster, J. Mosquitoes of Surinam. Amsterdam, Roy. Col. Inst., 1925. p. 415-418.

3. Howard, L. O.; Dyar, H. G. \& Knab, F. The mosquitoes of North and Central America and the West Indies. Washington, Carnegie Inst., 1917. p. 717-721.

4. Lane, J. Neotropical Culicidae. São Paulo, University of São Paulo, 1953. p. 692-695

5. Lane, J. Comunicação pessoal, 1961.

6. Senevet, G. \& Abonnenc, E. Les moustiques de la Guyanne. IV - Le genre Aedes. Arch. Inst. Pasteur Algér., 17:467-480, 1939.

7. Soper, F. L. \& Serafim, J. (Jr.) Note on the breeding of Aedes (Taeniorhynchus) fluviatilis, Lutz, in artificial water deposits. Amer. J. trop. Med., 13: $589-590,1933$ 